\title{
El ụișn Mirabīṭ (Cabanes, Castelló): alguns apunts Per al SeU estudi
}

\section{Marta Valls Llorens}

Universitat de Barcelona

e-mail: m.valls.llorens@gmail.com

\begin{tabular}{l|l|l|l|l|} 
Rebut: 2 maig 2017 & Revisat: 23 octubre 2017 & Acceptat: 15 novembre 2017 & Publicat: 21 desembre 2017 & do.1344/Svmma2017.10.4 \\
\hline
\end{tabular}

\section{Resum}

Aquest text mostra l'estat actual dels coneixements en relació a la fortalesa de Miravet (Cabanes, Castelló) i el seu territori amb la voluntat de proposar un seguit de línies de treball en relació al jaciment. Es compilen, doncs, els estudis de territori amb l'anàlisi de les fonts documentals relacionades i l'estudi arqueològic del propi jaciment, tant pel que fa a les estructures com als artefactes. Tot això amb la finalitat de posar en relació les diferents investigacions dutes a terme les darreres dècades $i$, sobretot, d'establir una base sobre la qual projectar noves actuacions $i$ línies de recerca en via a una desitjable futura excavació arqueològica que permeti un estudi complet i sistemàtic de la fortalesa.

Paraules clau: arqueologia, ḥiṣn, Šarq al-Andalus, territori, Miravet, Castelló

\begin{abstract}
This work analyses the medieval fortress of Miravet (Cabanes, Castelló) and its territory. Its goals are therefore to explore the current state of the art in medieval archaeology research for this region and to propose new actions to address the reamining gaps in this field. Written and archaeological sources are here compiled in order to approach this study from a multifocal perspective. In this way, this text aims to establish connections among the research lines followed over the last few decades and, most importantly, to lay the foundations for new efforts so as to develop a better understanding of this stronghold and its possessions. Hopefully, these will crystalise into future archaeological excavations in the site, which will allow a systematic analysis of it.
\end{abstract}

Key Words: archaeology, ḥiṣn, Šarq al-Andalus, territory, Miravet, Castelló 


\section{INTRODUCCIÓ}

Al llarg de les pàgines que composen aquest escrit tractarem de realitzar un estudi al voltant del jaciment de Miravet que permeti ampliar els coneixements sobre el poblament andalusí a la zona de coneguda com a plana de la Ribera de Cabanes o plana d'Orpesa, començant per l'estudi del jaciment de Miravet, situat al municipi de Cabanes. En aquest treball es mostra l'estat actual dels coneixements en relació al jaciment medieval de Miravet, situat a l'extrem més meridional de la Ribera de Cabanes (Castelló), així com les possibles línies de treball a desenvolupar de cara al futur. A partir de la presentació dels registres textuals i arqueològics d'aquesta fortalesa i els seus dominis es pretén proposar un primer projecte específic d'anàlisi que abordi les formes d'ocupació i organització d'aquest territori en època andalusina. És per això que cal deixar clar ja des de les primeres línies que la manca d'intervencions arqueològiques en aquest jaciment obliga a que l'objectiu del present escrit no sigui la presentació d'uns resultats concrets i concloents sinó més aviat posar sobre la taula un estat de la qüestió on es mostri de forma ordenada el conjunt de les informacions conegudes fins a l'actualitat, tant pel que fa a la pròpia fortificació com al territori que l'envolta.

El ḥiṣn de Miravet (Cabanes, Castelló) s'emplaça en un tossal situat a 1'extrem Nord-Est del paratge natural del Desert de les Palmes. La fortalesa es localitza sobre l'estreta cresta d'una barrera rocosa d'orientació Nord-Est/Sud-Oest i a 380 msnm (fig.1).

El topònim Miravet prové de l'evolució d'un plural de morabit (lloc de guaita i oració dels almoràvits). Les ràpites, ràbites i morabits eren fortaleses d'època andalusina que destacaven pel seu tarannà comunitari, militar i eremític (Huguet 1925). Tot i que, certament, l'origen etimològic que de forma comuna se li ha donat a Miravet es el de l'àrab morabit, M.C. Barceló planteja que es pugui tractar d'un topònim no aràbic (BARCELó 1983).

Fins a l'actualitat, alguns erudits locals com ara G. Andreu Valls (ANDreu 1975, 1988) i M. Betí, amb les aportacions publicades al Butlletí de la Societat Castellonenca de Cultura (BETí, 1921) han posat la mirada sobre l'estudi del jaciment de Miravet. Tanmateix, les investigacions més acurades i de caire eminentment arqueològic, es redueixen al sondeig i registre d'unes poques estructures per part d'A. Bazzana a finals dels anys 70, principalment, espais d'hàbitat (BAZZANA, Guichard 1979: 307), a més de l'estudi d'alguns dels materials ceràmics recuperats com a conseqüència d'aquests sondejos (BAzzANA 1992). Els resultats d'aquells treballs, realitzats en un moment en què tant l'arqueologia andalusina com, en general, l'arqueologia medieval es trobaven en una fase encara formativa al nostre territori, no han estat recollits en cap obra monogràfica sinó que la informació que se'n deriva es pot trobar integrada en diferents articles i llibres. També R. Jeanniard va realitzar un estudi arquitectònic mai publicat del castell el 1979, en què assajà d'analitzar l'evolució de les estructures des de l'època musulmana al període cristià 
(BAZZANA, Guichard1979: 310). Finalment, no pot passar desapercebuda l'obra monogràfica de M.O. Rousset sobre el jaciment, un material realment valuós per les descripcions tant escrites com gràtiques dels aparells constructius, a més d'algunes aportacions pel que fa al registre material del jaciment (RousSET 1988).

L'escassedat de documents escrits que parlen sobre aquest jaciment (BeTí 1921; ANDREu 1975), ha propiciat que l'actual estat de coneixements d'aquesta fortalesa estigui basat únicament en l'estudi dels seus aparells constructius i en el registre arqueològic recuperat d'altres jaciments situats en el mateix territori. A una escala més àmplia, la investigació pel que fa a aquest context resulta més prolífica i es manifesta tant en treballs de prospecció i recerca històrica com en anàlisis geomorfològiques (Flors 2009; Negre 2013; Sanjaume, Segura 1986).

Durant les darreres dècades, la recerca vinculada al coneixement del món rural andalusí ha avançat notablement gràcies a la recerca arqueològica, que ha contribuitt a reduir aquest buit de coneixement i a corregir errors (Navarro y Robles 1996; Acién 2008; Carvajal 2009; Gutiérrez 2012). És per això que en aquest text es defensa l'anàlisi del registre material com una eina clau per a l'ampliació del coneixement històric del món medieval. Aquest treball suposa, doncs, una oportunitat per tal d'apropar-se a l'estudi del món andalusí en un context que ofereix possibilitats d'abordar problemàtiques referents a la recerca en diversos àmbits i qüestions d'actualitat historiogràfica. Al mateix temps, però, també ha estat un repte el fet d'haver d'enfrontar-se a un registre habitualment desaparegut, a informacions disperses i a debats amb posicionaments en molts casos contraposats i enrocats. L'estudi que es presenta, per tant, es recolza fortament en l'arqueologia del territori com a via per plantejar futures línies d'actuació, ja que proporciona recursos que fan possible el plantejament d'hipòtesis i l'establiment de relacions entre les diferents fonts històriques que es troben al nostre abast ara mateix (Subías, Fiz 2004; Bolòs 2014; Negre 2015; SANCHO 2015).

\section{MIRAVET EN LES FONTS ESCRITES}

Tot i que, a priori, Miravet sembla estar absent a les fonts àrabs, el geògraf ceutí al-Idrīsī, que escriu al s. XII però empra de forma habitual fonts anteriors, adverteix de l'existència d'una fortificació amb el nom de hịșn Luriqāṭ que podria correspondre's amb el nostre objecte d'estudi. Situada a uns $80 \mathrm{~km}$ al sud de Tortosa, aquesta fortalesa apareix juntament als altres tres recintes defensius d'importància dels districtes sud de Tortosa: Šibart (Alcalà de Xivert), Kūna (Cervera del Maestrat) i Biniškula (Peníscola), ${ }^{1}$ totes ben identificades a través de les fonts escrites $\mathrm{i}$ arqueològiques (NEGRE 2013: 358-360). És també aquest autor qui localitza, entre els castells pertanyents al districte de Borriana, territori que limitaria amb Miravet pel sud, els hụșūn de

${ }^{1}$ AL-IdRīisi, 1989. Uns al-muhağ wa-rawḍ al-furağ, ed. i trad. de Jassim Abid Mizal. Los caminos de al-Andalus en el siglo XII, Madrid, CSIC: 97 
Muțurnāšs (Montornés, Benicàssim) i de J.ḍrāl (Fadrell, Castelló de la Plana), juntament als quals Miravet tancaria el pas viari a través del Desert de les Palmes. ${ }^{2}$

En aquest context el geògraf situa la fortalesa de Luriqāt a l'entorn de l'extrem sud del Prat de Cabanes, tot resseguint la via principal que transcorre per la façana litoral. El topònim ens aporta els detalls definitius per a la seva identificació atès que, històricament, el seu origen es vincula al de la mansio Lubricatum, esmentada pel Ravennate (s. VII) i la Guidonis Geografica (s. IX) i localitzada a l'entorn del jaciment tardoantic del Tancat, a Cabanes (Negre 2013b: 215). El topònim apareix novament en època andalusina citat a la Takmila d'Ibn al-Abbar ${ }^{3}$ i torna a localitzar-se, finalment, a la documentació llatina posterior a la conquesta, quan una turrem de Lupricato apareix com a límit entre els termes de Miravet i Sufera. ${ }^{4}$

Per la seva situació geogràfica i per l'entitat arqueològica que han demostrat, únicament Miravet i Orpesa podrien vincular-se a l'esmentada fortalesa de Llobregat. Tot i que alguns autors han tractat d'identificar el topònim de la tardorromana Lubricatum, l'altmedieval rahal al-Lobrecatí (Luriqāț) i la baixmedieval turris de Lupricato amb l'actual Torreblanca (BETí, 1921), sembla que una acurada lectura de la donació del rei en Jaume ens porta a descartar aquesta hipòtesi en tant que aquesta torre de Lupricato hauria d'estar sobre la via romana de l'interior i més o menys allunyada de la mar (Llobregat 1984), fet que situa Miravet com a ferm candidat per a aquesta assignació.

Tant als llocs de Miravet com d'Orpesa se'ls descriu ja a finals del s. XI, en temps de les incursions en terres valencianes de Rodrigo Díaz de Vivar, el Cid. Alguns autors donen notícia del setge i conquesta de Miravet per part del mercenari, fidel en aquell moment a la corona aragonesa, entre els anys 1090 o 1091 (Malo de Molina 1857: 72; Rovira i VirgiLi 1920: III, 602; Andreu 1975: 214, BETí, 1929:301). De ben segur, tant aquesta fortificació com les d'Orpesa i Montornés formaven part dels enclavaments sota control dels aragonesos durant aquests anys. ${ }^{5}$ Tanmateix, cal esperar a principis del s. XII, entre 1100 i 1103, per tindre notícies fefaents del domini efectiu dels aragonesos sobre Miravet i Orpesa, més concretament a la documentació de Pere I d'Aragó, on s'esmenta que Forti Hortiz (qui també ostentava la tinença de Montornés) era senyor en aquell moment de totes aquestes places. ${ }^{6}$ Aquest breu episodi, tanmateix, ens permet situar la cronolofia inicial de Miravet, com a mínim, a mitjans del s. XI. Orpesa seguirà apareixent com

\footnotetext{
${ }^{2}$ Ibid.: $95-96$

${ }^{3}$ Ibn AL-AbBar, 1887. At-Takmila li kitāb aṣ-șila, ed. de Francisco Codera. Madrid, Biblioteca Arábico-Hispana: 267

${ }^{4}$ Tortosa, AGV, lib. IV de Enaj., f. 29 i Manaments i Empares any 1262, lib. VI, man. 70, f. 31 (27 d'abril de 1225$)$ i Peníscola, ARC, lib. VII, p. 227 (3 de setembre de 1225). Colección diplomática de Jaime I el Conquistador (12171253) (CDJI), 1916-1919, ed. d'Ambrosio Huici. Valencia, Hijos de F. Vives Mora, docs. 41 i 44.

${ }^{5}$ Gesta Roderici Campidocti (GRC), 1911, ed. d'Adolfo Bonilla. Gestas de Rodrigo el Campeador. Madrid, Librería General de Victoriano Suárez: 83 i 88

${ }^{6}$ Orpin (?), AHN, San Juan, leg. 444, núm. 204 R, original[A] (juliol de 1100); Velilla de Cinca, ASLZ, Cartulari petit, fol-41 (novembre de 1100) i ACH, arm. Núm. IX, lig. 3, núm. 60, original (març de 1103). Colección Diplomática de Pedro I de Aragón y Navarra (DPI), 1951, ed. d’Antonio Ubieto. Zaragoza, Anúbar, docs. 85, 90 i 123.
} 
a objecte preferent de donació a les fonts escrites llatines, en aquest cas catalanes, des de mitjans del s. XII.7 Com a exemple, trobem un document de 1149 en el qual Ramon Berenguer IV i Garcia VI de Navarra acordaven el casament de Blanca de Navarra. En aquest document, a més, s'especificava que les conquestes a terres andalusines se les repartirien de forma amistosa i a parts iguals, inclosos els llocs de Daroca i Calataiud, al regne (sic) de Saragossa i Orpesa I Murel, un topònim que alguns autors han associat a Morella. ${ }^{8}$ Així, tot i que en primera instància no s'esmenti clarament Miravet, aquest document certifica la persistència de la imatge d'aquest territori, amb Orpesa al capdavant, com a frontera a conquerir, tot seguint l'exemple de rei aragonès, que ja establí allà un domini efímer a finals del s. XI.

Així mateix, Orpesa és esmentada en les fonts àrabs de mitjans del s. XII, que hi fan referència com a un important amarrador (marsà 'Aqaba Abǐša). ${ }^{9}$ Igualment, ens recolzem en les fonts àrabs d'inicis del $\mathrm{s}$. XIII per proposar la seva identificació com a una petita urbs portuària. Són diversos els textos amb que Ibn al-Abbar recolza aquesta idea, en fer esment d'ella com a cap d'un districte ('amal) en la frontera oriental de València, del qual depenia el lloc de Luriqāt. ${ }^{10}$ La importància d'Orpesa es veu encara més accentuada si tenim en compte que controlava la via principal de comunicació entre el litoral tortosí i el valencià de manera que al-Idrīsī situava aquest enclavament entre Peníscola i Borriana proper a la mar per on discorre aquesta important via. Tot i que descriu la dificultat per travessar aquest cim, que en realitat amb prou feines supera els $100 \mathrm{~m}$ d'altitud, podem pensar que aquesta exageració ve donada pel contrast amb el territori pla que l'envolta (Piqueras, Fansa 2010: 10). D'aquesta manera, Miravet se situaria juntament amb Sufera, Montornés i Fadrell esglaonant una via de comunicació secundària i alternativa que travessaria pel bell-mig del Desert de les Palmes (Fig. 2).

Així doncs, tot indica que el geògraf ceutí identificà una fortalesa, de la qual probablement en desconeixia la denominació exacta (Miravet) amb el nom del territori en que es trobava (Llobregat), un ètim que apunta a un lloc fangós, en referència probablement a l'entorn del Prat de Cabanes (Martí, Negre 2014). Aquesta substitució del topònim de certes fortaleses pel nom del territori en que es trobaven ha estat identificada en altres casos com el de Cervera del Maestrat (Ğirbīra), anomenat com a hịịn Kūna, en referència al territori conformat per les valls dels rius Cervol i Sénia, vallis de Chona, Vallisconae o Uayl de Cona a la documentació llatina de la primera meitat del s. XII (NeGRE 2013: 130-131).

\footnotetext{
${ }^{7}$ El Puig, ACA Barcelona, Cancelleria Reial, reg. 5, f. 8r, original (6 de març de 1238). Arxiu Virtual Jaume I (AVJI), Universitat Jaume I, Castelló, doc. 1796, http://www.jaumeprimer.uji.es/ [23/04/2017]

${ }^{8}$ ACA, Cancelleria, pergs, Ramon Berenguer IV, carp. 38, núm. 214 (1 de juliol de 1149). Els pergamins de l'Arxiu Comtal de Barcelona, de Ramon Berenguer II a Ramon Berenguer IV (ACB) ed. i est. d'Ignasi J. Baiges, Gaspar Feliu i Josep M. Salrach (dirs.). Barcelona, Fundació Noguera 2010, DOC. 884

${ }^{9}$ AL-IDRİ̄ī, op. cit.: 96

${ }^{10}$ IBN AL-ABBAR, op. cit.: 1512
} 
Les següents notícies de què disposem ens porten al s. XIII, durant la preparació, execució i gestió de la conquesta militar i colonització dels territoris valencians a mans de Jaume I d'Aragó. Pocs anys abans d'iniciar la conquesta, el 1225, el rei ja havia donat els castells i territoris de Miravet, Sufera i Fadrell, al bisbe de Tortosa, ${ }^{11}$ tot confirmant l'extensió de la nova diòcesi tortosina fins Almenara, tal com havia dotat el seu avi Alfons. ${ }^{12}$ Tal com ho especifiquen aquests documents, les donacions serviren com a recompensa per l'ajuda constant, en forma de finançament, que el prelat oferí al monarca durant les campanyes militars en terres andalusines. Sigui com sigui, el cert és que aquests textos aporten informació de gran rellevància per a l'estudi de Miravet i el seu territori, tot fent una descripció exhaustiva dels límits del seu terme i de la toponímia àrab que encara conservava, llavors, tot el seu potencial explicatiu.

Als volts de la segona meitat del 1231, trobem al rei Jaume a Alcanyís preparant una nova campanya militar per a la conquesta efectiva de València i establint, en primer terme, la presa de Borriana. ${ }^{13}$ Aquest fet es produeix a inicis de l'estiu de l'any 1231, tot establint un cap de pont en territori musulmà i aprofitant la presa d'Ares, que li donava el control sobre la via de comunicació cap al sud pel pas de la Vall d'Alba i de Borriol (Negre 2013b: 220). Amb aquesta acció i la caiguda definitiva de Peníscola, templers i hospitalers avancen per les vies costanera i interior respectivament i conquereixen les fortaleses de Cervera i Xivert, mentre que el rei i la seva host avancen des del sud conquerint Fadrell, Borriol, les Coves de Vinromà, 1'Alcalatén i Vilafamés.

És durant aquesta campanya, a la tardor de 1233, que el castell de Miravet degué passar definitivament a mans cristianes, sense oposar excessiva resistència.

La carta de poblament atorgada a Cabanes en $1243,{ }^{14}$ seguida de la que es concedí a les seves alqueries de Beniaixo i Tahalfazar (Bell-1loc) el 1250 ${ }^{15}$ i finalment el permís que en 1260 permeté a la vila realitzar un mercat setmanal els dimecres, potenciaren l'activitat d'aquest enclavament en detriment del castell que, tot i ostentar la titularitat de la Tinença de Miravet, resultava poc accessible. Tanmateix, en època baixmedieval la documentació cristiana establia encara de forma clara que dintre dels dominis d'aquest castell es trobaven els llocs de Cabanes, Bell-1loc, Torreblanca i Albalat. ${ }^{16}$

\footnotetext{
${ }^{11}$ IBN AL-ABBAR, op. cit.: 1512

12 Tarragona, Comú del Capítol, 1, 4 (700-610) (28 de novembre de 1178). Diplomatari de la Catedral de Tortosa (1062-1193) (DCT), 1997, ed. d’Antoni Virgili. Barcelona, Fundació Noguera, doc. 301.

${ }^{13}$ Llibre dels Feits (LF), 2007, ed. de Ferran Soldevila a Les Quatre Grans Cròniques. Barcelona, Institut d'Estudis Catalans: 218

${ }^{14}$ Cartes de Poblament Medievals Valencianes (CPMV), 1991, ed. d'Enric Guinot. València, Generalitat Valenciana: $170-173$

15 Íbid.: 218-220

${ }^{16}$ Colección de Documentos Iinéditos del Archivo General de la Corona de Aragón (CDIAGCA), 1858, ed. de Pròsper de Bofarull. Barcelona, Impremta de l'Arxiu, vol. XV, t. II: 258
} 
Es coneix que el 1459, el rector responsable de l'església de Miravet era Bonanato Pujades, que el 1472 l'encara existent Tinença de Miravet estava sota control d'Otó de Montcada i que el despoblament del nucli s'inicià al s. XVI, moment en el que el nucli depenia ja judicialment de Cabanes (BETi 1921). Finalment i de forma progressiva, tant Miravet com Albalat es despoblaren fins quedar, finalment, sota control de Cabanes (ANDREu 1975: 220-223).

\section{MIRAVET EN EL SEU CONTEXT ARQUEOLÒGIC MÉS IMMEDIAT}

Vist això, degut a la manca d'un major volum de documentació al respecte, l'única manera de precisar la datació d'aquest jaciment seria la seva excavació arqueològica en extensió i l'estudi acurat de les restes materials. Aquesta actuació hauria d'anar vinculada, a més, a l'estudi dels materials corresponents a altres llocs fortificats propers, també de cronologia andalusina, que ja han estat excavats de forma sistemàtica, com el castell de Xivert i el d'Orpesa (ARQUer, Falomir 2008; SELMA 2014). Entre altres jaciments en alçada i construccions singulars vinculades, trobem també l'emplaçament de Sufera, associat a una cronologia andalusina (Bazzana, Guichard 1977), a més de les fortaleses de Montornès (Benicàssim) i Fadrell (Castelló de la Plana), que acabarien de tancar el control del pas a través del massís del Desert de les Palmes (Negre 2013b).

Més al nord destaca el jaciment andalusí de Santa Llúcia (Alcossebre), actualment en excavació, que se situa a sobre d'un assentament de l'edat del bronze i el primer ferro. A l'interior, a banda i banda de la vall de Xivert, trobem el jaciment del Tossal de la Vila (Serra d'en Garceran), on s'està excavant un enclavament fortificat andalusí superposat a un altre de cronologia novament protohistòrica (Neumaier, de Antonio, Vizcaíno 1998; Arquer, Falomir 2008).

La majoria d'aquests casos il·lustren una problemàtica habitual en l'arqueologia d'al-Andalus, vinculada a la detecció de jaciments medievals islàmics reocupant l'emplaçament d'hàbitats protohistòrics i antics, tot reaprofitant els seus materials constructius (Cressier 2001; AzUAR 2005). Aquesta hipòtesi es posa sobre la taula als diversos treballs sobre la zona meridional del Šarq al-Andalus, on es fa notar un decreixement dels assentaments situats en les planes, les lleres dels rius i les principals vies de comunicació des del s.V en favor d'una reocupació de les zones de muntanya (Torró, Ferrer 1985; Reynolds 1993; Boone 2009: 46). En qualsevol cas, estem tractant un període severament afectat per la desarticulació dels grans mercats comercials mediterranis que marcarà els nous sistemes de producció al món rural i l'aprofitament d'espais marginals que donaran resposta a noves estratègies de poblament.

De cronologia més tardana, cal destacar també les construccions fortificades del castell i l'església d'Albalat com a exemples de fortificacions cristianes de conquesta. Al mateix temps, s'ha de posar en valor el paper de les tres torres vigia de la Ribera de Cabanes, més la de Torrelasal, les quals s'adscriuen a una cronologia compresa entre els segles XV i XVI i que, per tant, només 
podrien relacionar-se amb Miravet en època cristiana. ${ }^{17}$ A més d'aquestes construccions singulars, existeix tot un seguit de jaciments arqueològics que cal tenir també en compte (fig.3):

En primer lloc, hem de destacar la importància del jaciment proper de Torrelasal, excavat sistemàticament els últims anys $\mathrm{i}$ on es documenta un important nucli de poblament entre els segles X i XIII (Flors 2009: 239). A més, els treballs de prospecció dirigits pel mateix equip a la Ribera de Cabanes $\mathrm{i}$, més concretament, al barranc de Miravet han permès documentar una sèrie de petits jaciments amb materials ceràmics corresponents a aquesta mateixa cronologia que s'han identificar com a alqueries (FlORS 2009: 52, PÉREz 2014: 8). Es tracta en tots casos d'assentaments rurals de petites dimensions que caldria posar en relació amb l'explotació agrícola i ramadera d'aquestes terres sota domini d'alguna fortificació amb funcions territorials, que en el cas que aquí ens ocupa correspondrien a les fortaleses de Miravet i Orpesa. Es tracta de jaciments sobre l'emplaçament dels quals trobem en molts casos masos actuals, fet comprensible si tenim en compte la seva situació geogràfica a les lleres d'un curs estacional i la seva proximitat a punts de captació d'aigua (fonts de Miravet i del Perelló). Aquestes tasques de prospecció, doncs, ens constaten una ocupació del barranc ja des del s.X caracteritzada per una sèrie d'assentaments amb una evident funcionalitat agrícola basada en sistemes de regadiu. Com a conseqüència d'això, s'ha trobat material en superfície a la vora d'aquest barranc, al llarg del recorregut de l'anomenat camí de la Fusta, la via de comunicació que principalment domina la fortificació i la qual detallarem en endavant i al voltant de la qual trobem també algunes infraestructures hidràuliques com ara el conegut com a aljub d'Orpesa o de Miravet. Aquest fet s'ha interpretat tradicionalment com a un nou model d'explotació territorial organitzat en base a punts defensius estratègics relacionats amb les vies de comunicació i que servien al seu torn com a refugi de les comunitats camperoles que habitaven a banda i banda d'aquestes. Aquest model, segons la datació de les restes trobades en prospecció, es perpetuaria fins la primera meitat del s.XIII amb la conquesta cristiana, quan s'abandonen la majoria d'aquests llocs d'hàbitat, així com els sistemes de regadiu associats. En endavant, solament semblen ser ocupats els punts més estratègics: castells i nuclis de població més forts com podrien ser les viles d'Orpesa, Cabanes, Torreblanca, el castell de Miravet i la nova creació d'Albalat (FLoRs 2009: 544-545).

\section{LES FUNCIONS DE LA FORTALESA DE MIRAVET}

Sobre les funcions que aquest lloc pogué desenvolupar al llarg de la història, els diferents treballs realitzats condueixen directament al debat sobre el paper de les fortaleses (ḥuṣunn) en la formació i estructuració de la societat andalusina. Des dels anys 80, aquest debat va posar sobre la taula dues postures enfrontades: aquells que descrivien les fortificacions com a elements emergents

\footnotetext{
${ }^{17}$ Inventari General del Patrimoni Cultural Valencià (IGPCV), Direcció General del Patrimoni Cultural Valencià, Generalitat Valenciana, http://www.ceice.gva.es/ca/web/patrimonio-cultural-y-museos/inventario-general [14/04/2017]
} 
d'una societat segmentària i tribal (BAZZANA, Guichard 1979; BAZZANA 1983 i 1992) i aquells que les concebien com a la conseqüència d'una nova societat estatal progressivament islamitzada (Azuar 1989). Els primers, que utilitzaren precisament l'exemple de Miravet, entre d'altres, plantejaven una dinàmica general de creació de fortificacions per part de comunitats camperoles relativament independents com a lloc de refugi. Per contra, el segon grup defensava la iniciativa estatal en la construcció d'aquests elements monumentals vinculats a la defensa i a l'organització dels nous dominis andalusins. Les discussions han tingut continuitat al llarg de les darreres dècades, amb propostes d'interpretació més properes a un o altre model a partir de diferents casos d'estudi regionals (Torró 1998; MARTí, Negre 2014). Amb tot, cal destacar que els treballs més recents centren l'atenció en la variabilitat de funcions d'aquests emplaçaments, així com la seva complexitat, que no pot encabir-se en models unificats i homogenis per a tota la Península.

De forma genèrica, la fortalesa de Miravet sembla estar vinculada, per posició i abast visual, al control del pas entre el Prat de Cabanes i la plana de Fadrell, formada per les terrasses al-luvials del riu Sec de Borriol, a través del massís muntanyós conformat pel Desert de les Palmes. Aquest control s'exerciria juntament amb les fortaleses de Sufera (Cabanes), Montornés (Benicàssim) i Fadrell (Castelló de la Plana), que esglaonarien la via al llarg d'aquest pas (Negre 2013b). Es tracta, doncs, d'una ubicació estratègica en tant que el seu camp d'observació permet controlar tant el pas muntanyenc com un ampli segment de costa, per on transcorre el principal eix viari entre Tortosa i València. Gràcies a aquesta posició privilegiada es podia controlar el trànsit al llarg de la façana litoral llevantina, un eix privilegiat ja des del s.VII, en detriment de l'artèria vial interior a través de la Via Augusta (Negre 2013b).

Des de la muntanya on s'aixeca el jaciment es pot resseguir també l'antic camí de la Fusta. Aquesta via, que comença al fondejador del jaciment de Torrelasal i que comprèn una cronologia d'ús des d'època ibera, enllaça a la seva arribada a Cabanes amb l'antic camí de Vistabella. Des d'aquest punt, passa per la vora de l'arc romà de Cabanes, on creua amb la Via Augusta i s'endinsa pel terme de la Vall d'Alba en direcció a Atzeneta del Maestrat essent, sense dubte, una antiga via de gran importància agropecuària i comercial (ARASA, ABAD 1989: 30). Una de les principals funcions que tenien aquestes vies secundàries era la difusió dels productes d'importació que arribaven des de la mar cap a les terres de l'interior (ARASA, Rosselló 1995: 121).

Si tenim en compte que les fonts àrabs fan esment de la presència d'un amarrador, anomenat 'Aqaba Abīša, en aquest mateix sector de la costa, bé en referència a l'assentament andalusí de Torrelasal o al d'Orpesa, és plausible pensar que aquesta via de penetració cap a l'interior seguiria en funcionament en època medieval. ${ }^{18}$ Sembla, doncs, que la funció de vigilància dels camins jugà un paper fonamental en l'elecció de l'emplaçament de Miravet i que la seva posició clau en l'entramat viari andalusí pogué ser un dels motors per desenvolupar un assentament estable a la vora.

$\overline{{ }^{18} \text { AL-IDRĪsī op. cit.: } 95-96}$ 
A banda d'una situació geogràfica privilegiada, el poblat compta amb una sèrie d'elements característics dels assentaments fortificats com ara la muralla perimetral, instal·lacions hidràuliques (aljubs, cisternes i sistemes d'evacuació d'aigües), una mesquita i un gran nombre d'habitatges (Lorrio, SÁnchez de Prado 2008; SÉnAC 2005). Tot això sembla indicar que es tracta d'un poblat amb un hàbitat estable i considerable que serviria, a més, al final de la fase andalusina, de refugi per als habitants de les alqueries properes.

\section{MORFOLOGIA DE MIRAVET: MURALLA, FORTALESA MESQUITA I POBLAT}

El jaciment de Miravet s'estén al llarg d'una plataforma de 200m delimitada per un mur perimetral que compta amb una torre de planta rectangular en el seu extrem Nord-Est. A la part més meridional del jaciment, el mur de tancament recolza contra el recinte principal, en alçada. Més a baix, trobem un seguit de construccions en pedra identificades com a poblat. Amb una gènesi corresponent al període andalusí, aquest es perllongaria fins època cristiana, tot i que molt possiblement la seva formació seria més tardana a la del recinte principal. En una zona central dins del poblat es localitza un edifici singular identificat amb una mesquita rural que seria posteriorment aprofitada com a església i, amb l'abandonament del poblat, com a ermita (fig.4).

A nivell constructiu, quasi bé la totalitat del jaciment es conforma de pedra calcària lligada en sec o amb morter. A més, veiem l'ús de pedra sorrenca vermella per a la fabricació de morter i la construcció d'alguns elements decoratius en l'edificació de la mesquita i del recinte superior: punts per al recolzament de bigues, arcades o carreus usats en el travat d'algunes cantonades. Tanmateix, tant la tipologia de carreus ben escairats com l'ús de la pedra sorrenca es relaciona sovint amb les estructures, reformes o ampliacions d'època feudal, mentre que la majoria d'estructures andalusines s'aixequen mitjançant murs de maçoneria. Encara més, si observem la fortificació des de la zona sud del jaciment, veiem clarament que la roca mare que esculpeix la muntanya està formada principalment per una base calcària sobre la qual es recolza la construcció dels paraments del recinte superior, el qual serà descrit més endavant. Tot $\mathrm{i}$ això, aquest aflorament també compta amb una important veta de pedra sorrenca vermella que travessa la zona est del tossal. Conseqüentment, és plausible plantejar la utilització de recursos locals propers per a la construcció de les diverses estructures del jaciment. També, si ens fixem en la composició del morter que uneix els carreus de pedra, observem fàcilment com hi ha una part proporcional de sorra major a la de calç. Aquesta sorra, a més, es mostra amb una tonalitat vermellosa que sembla indicar una procedència directa de l'esmicolat de les pedres vermelloses de la mateixa muntanya.

El recinte superior es troba molt alterat per les reformes d'època cristiana. A grans trets, està composat per una part baixa on trobem l'entrada, una torre trapezoïdal de carreus ben escairats, la capella i un cor composat d'arcs. El castell custòdia també una cisterna de grans dimensions (BAZZANA 1992: 297) i un aljub. Sembla ser que l'entrada principal se situava a la part central i 
donaria accés directe al cor; tanmateix, s'evidencia una segona entrada a l'Est de la fortificació que possiblement tindria una cronologia més tardana i que estaria vinculada amb una restauració (RousSET 1988: 55).

Pel que fa a l'estudi dels paraments de la fortalesa, trobem una gran diversitat i una innegable feina de reconstruccions i modificacions al llarg dels segles. Per començar, la part exterior de la fortalesa es tanca amb una muralla perimetral pròpia construïda en la seva base amb pedra calcària i caracteritzada per un lleuger eixamplament en la part inferior per tal de reforçar el recolzament directe sobre la roca (Rousset 1988: 54). La part superior s'aixeca amb tàpia de fang coronada amb merlets, de manera que suposa l'única evidència d'obra en terra que trobem en tot el jaciment. Aquest aixecament de tàpia portaria a situar aquesta reforma del recinte fortificat, probablement, en època almohade, tot i que no és una tècnica desconeguda amb anterioritat (Azuar 2005; CANivell, Graciani 2015). L'obra inferior a la tàpia, per tant, caldria associar-la a una cronologia anterior, caracteritzada per l'ús de maçoneria que recolza en la seva base sobre carreus en pedra seca més grans i escairats (fig. 5). La poca representació de la construcció en argila que observem a Miravet juntament amb la potència dels murs de pedra millor conservats $\mathrm{i}$ l'absència de restes de material argilós provinent de murs caiguts ens parlarien d'una construcció pràcticament exclusiva en pedra. Això podria explicar-se per la seva situació a gran alçada, que dificultaria el transport d'argila i d'aigua.

El mur perimetral del poblat té una extensió de $550 \mathrm{~m}$ adaptats al relleu natural i presenta una homogeneitat tal pel que fa als morters utilitzats que fa que les petites diferències que trobem en alguns trams s'expliquin més aviat per qüestions de conservació que cronotipològiques (RousSET 1988: 41). Els estudis han constatat que inicialment la muralla es recolzava sobre les primeres cases del poblat i que, per tant, seria posterior a la construcció d'aquest. El pas de ronda, que s'establiria en una fase encara més tardana, estaria construï amb fustes que se sustentarien gràcies a bigues fixades sobre el mur (Rousset 1988: 54), de les quals encara queden evidències en el parament exterior de la muralla.

Quant a la mesquita de Miravet, s'ubica al centre del poblat, al costat d'una plataforma a tall de placeta. La seva planta segueix un esquema apaïsat i senzill d'una sola nau sense minaret, possiblement per la manca d'espai. El mihrāb, orientat cap al Sud-Est i situat al centre de l'alquibla, és semicircular i estava cobert per una volta de forn (CALvo 2004: 54) (fig.6). L'espai interior es va dividir en època cristiana en quatre compartiments mitjançant tres arcs diafragmàtics, de forma que l'orientació funcional de l'edifici es va desplaçar 90 (BAZzANA 1992: 299) (fig.7).

Es tracta d'una mesquita rural en hiṣn on se centralitzaria l'oració setmanal d'un poblament dispers, com en el cas del Molón (Lorrio, Sánchez de Prado 2008) o de Velefique (Angelé, CRESSIER 1990). Les característiques constructives de l'oratori no permeten precisar la seva 
cronologia, tot i que la forma del mihrāb sembla correspondre amb models de mesquites rurals del s.X o més recents (CALvo 2004: 55-56).

Atenent al cas del poblat, cal esmentar algunes particularitats sobre aquest tipus d'hàbitats agregats en la historiografia andalusina. Segons alguns autors, la formació d'al-Andalus va generalitzar, des de les valls de l'Ebre fins el Magreb, uns esquemes urbanístics i culturals homogenis que han perdurat, en molts casos, fins fa pocs segles (BAZZANA 2002). Altres autors posen en dubte aquestes generalitzacions i proposen una anàlisi més exhaustiva d'aquests àmbits que permeti determinar diferències en l'organització i les característiques socials més enllà de les semblances a nivell morfològic (GUTIÉRREZ 2012b).

El poblat de Miravet mostra una tipologia constructiva en pedra que, podem suposar, es combinava amb elements vegetals (forats i punts de suport per a bigues als murs). La seva construcció és prou heterogènia, $i$ es poden diferenciar diversos models constructius. El primer sistema es caracteritza per ser un tipus de parament prou heterogeni format, d'una banda, per grans blocs ben escairats i, de l'altra, per blocs grans i mitjans sense escairar que es calçarien mitjançant petites pedres. Aquests murs estarien lligats amb un morter molt lleuger o, directament, amb terra. Referent a la segona tipologia constructiva, està formada per grans blocs a la base i mitjans a la part superior. Ambdós estan ben escairats i els carreus es lliguen amb capes espesses de morter. Quan comptem amb pedres de menor mida, aquestes s'estableixen de forma obliqua, a mode d'opus spicatum, per tal de mantenir l'homogeneïtat en el gruix dels murs. El tercer grup és semblant al primer però usa carreus més regulars $\mathrm{i}$ un morter encara més espès. S'usa per a la part exterior de les cases $\mathrm{i}$ per a murs particularment exposats, com ara el tancament perimetral. A més, aquests paraments es troben sovint associats a sistemes d'evaquació d'aigües i a forats de bigues. Tant aquest grup com el segon es relacionen amb algunes construccions domèstiques de Xivert que s'han associat tradicionalment, amb les mateixes limitacions que podem observar a Miravet, al període de taifes (s. XI-XII). La quarta tipologia es caracteritza per l'ús de la tàpia i de blocs ben escairats per a la construcció d'angles i per a l'enquadrament de les obertures. Aquesta darrera, la trobaríem exclusivament en la construcció del recinte superior i correspondria a reformes d'època feudal. Finalment, es localitzen una sèrie de paraments construïts amb pedra seca sovint calçats amb pedres més petites o simplement amb l'apilament de grans blocs (Rousset 1988: 52,53).

Pel que fa a l'esquema director de l'espai domèstic, trobem una varietat que respon a models diversos que diferenciarien l'habitatge unicel·lular del complex. D'una banda, els habitatges unicel·lulars estan conformats per una estructura massiva rectangular, formada per una única habitació polifuncional sense finestres organitzada entorn d'una llar. Aquesta modalitat estructural, tot i que pot estar intracompartimentada o presentar estructures juxtaposades, té un funcionament $i$ accés únic i sovint s'organitza en tres nivells (estable, hàbitat i terrassa). D'altra banda, les edificacions domèstiques de tipus més complex es conformen de diversos espais que 
responen a funcions concretes i que es relacionen entre elles mitjançant aquest espai central, que serà més o menys definit, segons parlem d'esquemes de mòduls associats, agregats o de pati central. Aquesta darrera modalitat es consolidarà en època califal i suposarà una evidència de segmentació social en tant que sovint trobem més d'una llar repartides en els diferents espais (BAZZANA 2002; GuTIÉRREZ 2012b).

La tipologia de cases que podem observar a Miravet correspon a la d'habitatges petits distribuitts al voltant d'un cor central. Cada casa està situada, al mateix temps, sobre àrees on sobresurt la roca mare de la muntanya, de manera que conforma una defensa natural (BAZzANa 2002: 218). El fet que les construccions segueixin el relleu natural de la muntanya fa que, en principi, la distribució de les estructures mostri un cert desordre que després es va compensant amb l'ajuda d'estances complementàries (BAZZANA 2002: 299).

D'entre les cases estudiades al jaciment de Miravet trobem les estructures 221, 222 i 203 (BAZZANA 2002: 219-226). En el cas de les dues primeres, han pogut ser identificades gràcies a les dades que dóna A. Bazzana sobre el seu posicionament ja que, malauradament, en l'actualitat es troben pràcticament arrasades i irrecognoscibles. En el cas de la primera, per contra, encara es pot observar el buidatge fins a la roca mare fet per A. Bazzana a finals dels anys 70 del s.XX. Referent a la casa 203 (fig.8), A. Bazzana descriu un conjunt allargat condicionat pel precipici que la limita. L'estança principal estaria associada a un cor central tancat per un muret baix. Aquesta es complementaria amb els àmbits 2035 (cuina i emmagatzemantge) i 2036, a més d'una zona d'estabulació d'animals (BAzZANA 1992 i 2002). Tot i que l'espai domèstic 203 va ser interpretat per A. Bazzana primerament com a una estructura formada per diferents àmbits contemporanis, més tard es va proposar un conjunt conformat a partir d'una estructura unicel-lular a la qual s'anirien afegint diferents mòduls (Bazzana 2011: 59). Aquesta evolució en la conformació de les estructures domèstiques podria ser mostra també d'una evolució cronològica pel que fa al poblat, des de les construccions més senzilles a altres de més complexes. Seria necessària, doncs, una profunda anàlisi estratigràfica d'aquestes àrees.

\section{EL REGISTRE CERÀMIC DE MIRAVET}

L'estudi de les ceràmiques recuperades al jaciment és un element clau per tal de veure l'evolució de les estructures constructives i també la seva cronologia. A falta d'una descripció acurada dels materials recuperats durant les excavacions dels anys $70 \mathrm{i}$ de la impossibilitat d'executar-ne de noves ara mateix, solament es poden posar sobre la taula les observacions dutes a terme per aquells que n'estudiaren el registre (Rousset 1988; BAZZANa 1992):

En l'espai 2035 s'observa un major percentatge de formes tancades (olles, càntirs, ampolles i gerres) que d'obertes (gibrells, bols i ataifors), així com un baix nombre de fragments decorats. 
També s'ha trobat un gran nombre de fragments de peces amb cobertes vidrades verdes i melades que els autors vinculen a una cronologia ja del s. XII, a més d'una llàntia (Rousset 1988: 121; BAZZANA 1992: 148). L'absència de ceràmica blava i blanca i de ceràmica de Paterna ha servit per identificar l'abandonament d'aquest espai al s. XIII.

La casa 204 mostra característiques semblants a l'anterior però amb menys diferència entre formes obertes i tancades, un menor nombre de ceràmiques d'emmagatzematge i un augment pel que fa a les mostres de fragments decorats, sobretot vidrats blancs i decoracions amb manganès. Això ens mostraria, segons els autors, una ocupació més tardana d'aquesta estança en comparació amb la 203 (RousSET 1988: 119-120). La casa 222 presenta la mateixa proporció entre formes tancades i obertes, així com entre vaixella de taula i de cuina, que la 2035. Tanmateix, la ceràmica d'emmagatzematge es troba menys representada. Aquesta casa, que també presenta una llar de

foc, estaria ocupada vers el s. XV, tal i com mostra la presència de cobertes estanníferes i de decoracions en blau i blanc (Rousset 1988: 121).

Pel que fa al recinte superior, la relació entre formes obertes i tancades és equitativa. Tanmateix, serà en aquest indret on trobarem el percentatge més alt de fragments decorats, sobretot decoracions amb manganès, incises o en relleu, amb menor presència dels tipus més tardans blaus i blancs o de ceràmica de Paterna (Rousset 1988: 121).

De forma general, els autors proposen que la poca presència de decoracions amb verd i manganès, així com de manganès sota coberta vidrada melada, indica que el jaciment no seria anterior al s. XI (Rousset 1988: 121). Malauradament, la impossibilitat d'analitzar el registre ceràmic recuperat durant les intervencions, actualment desaparegut, no permet aprofundir gaire en aquesta línia.

\section{CONCLUSIONS I NOVES LÍNIES DE TREBALL PER A UNA RECERCA INTEGRADORA}

La informació plantejada sobre el jaciment de Miravet no és més que un punt de partida per a l'anàlisi del període islàmic a la zona de la plana de la Ribera de Cabanes. Tenint en compte que la informació que ens donen les fonts escrites és realment limitada i fragmentària i que el registre arqueològic no ha estat de moment explotat de forma efectiva cal considerar que els resultats d'aquest estudi no poden sinó limitar-se a un estat de la qüestió i a aportar pinzellades a grans trets sobre la gènesi i desenvolupament d'aquest jaciment.

Així doncs, podem establir una seqüència cronològica aproximada en base a les tasques de prospecció, estudi de paraments i anàlisi de les fonts escrites que s'exposen al llarg del text. En base a això, les fonts esmenten el lloc de Miravet des de finals del s. XI, encara que de manera poc concreta. D'altra banda, es constata una ocupació de tipus rural a la llera del barranc de 
Miravet ja des del s.X que sembla associar-se a aquesta fortalesa. D'una banda, això podria ser element indicatiu de l'existència d'una població camperola prèvia a la construcció de la fortificació o, d'altra banda, d'un naixement més o menys contemporani d'ambdues realitats (les alqueries i la fortificació) que no es posa de manifest en la documentació escrita fins a un segle més tard, atenent a descriure solament el nucli principal. D'altra banda, la ceràmica recollida a les cales realitzades per A. Bazzana en el poblat aporta una datació compresa entre els segles XII i XIII, arribant la ocupació, en alguns casos, al s. XV, moment d'abandonament definitiu del lloc. Pel que fa a la muralla perimetral del poblat i atenent a l'estudi de paraments i la relació entre els murs dels habitatges i aquesta, se'ns presenta, tal com hem dit, com a posterior a la construcció del mateix. Entrant ara en l'estudi de les dades provinents del recinte superior, una major mostra de ceràmiques tardanes $i$ algunes reparacions en el parament ens parlen de la reutilització $i$ restauració d'aquesta zona durant el període feudal. Així doncs, a grans trets, podríem parlar de l'existència d'una primera fortificació associada a una sèrie d'alqueries a la plana com a mínim des del s.XI que perduren fins el s.XIII. Al mateix temps, i a partir del s. XII com a mínim es data l'existència del poblat en el propi jaciment del cim del tossal, que compta amb diverses fases de construcció que s'estenen fins el $\mathrm{s}$. XV amb l'abandonament del lloc i que es protegirà amb el temps mitjançant un mur perimetral. Aquestes fases semblen anar associades al procés de conquesta cristiana, moment en que la mesquita es transforma en església i, al seu torn, es realitzen una sèrie de reconstruccions al recinte superior que eclipsen pràcticament qualsevol resta de construcció de moment andalusí. Nogensmenys, s'ha de ser conscients que aquestes idees prèvies es fonamenten en un estudi molt primerenc $i$ que calen ser contrastades mitjançant l'excavació sistemàtica i l'estudi de materials del jaciment.

A nivell territorial, tot sembla indicar que Miravet seria el punt de domini tant del camí de la Fusta i com de les alqueries ubicades a les seves immediacions. Tanmateix, tot apunta que l'establiment fort de la zona en època andalusina podria més bé correspondre's al castell d'Orpesa, amb un important amarrador i als peus del qual passa la via de comunicació principal de la costa. Per la seva part, Miravet prendria importància com a lloc estratègic de control de les vies de comunicació de la zona més septentrional del Desert de les Palmes i de l'entrada al mateix paratge. En relació a això, el camí de la Fusta pren gran importància per ser una de les vies clau de comunicació entre la costa i l'interior i el Desert de les Palmes resulta també de gran importància com a zona fronterera.

A partir d'aquest treball previ i de cara a un futur, la creació d'unes pautes de prospecció racionals permetrà optimitzar els esforços en el moment d'encarar-se al treball de camp. Així, cal tenir en compte la revisió dels llocs identificats com a jaciments protohistòrics, analitzar amb deteniment la toponímia menor i restituir la xarxa viària tradicional, ineludiblement vinculada als llocs d'hàbitat. El registre ceràmic obtingut d'aquestes intervencions s'haurà d'acarar necessàriament amb les excavacions sistemàtiques de cronologia similar dutes a terme al territori per tal de crear una cronotipologia bàsica per a la seriació dels jaciments arqueològics (ARQUER, FAlOMIR 2008; Flors 2009; SElma 2014). 
Pel que fa a la vertebració de la fortalesa amb aquest poblament rural, l'excavació de Miravet i d'alguns dels assentaments rurals de les seves rodalies suposaria una oportunitat extraordinària per tal d'analitzar la seva funció i evolució territorial. L'anàlisi dels materials arqueològics permetria aclarir de forma definitiva si prèviament a la instal·lació de la fortificació ja existia un poblament rural. La datació proposada per a la fundació de Miravet en aquest treball seria, a més, coherent amb els estudis de J. Torró, en els quals afirma que les fortificacions anteriors al s. X representen tan sols un 10\% del total de les fortificacions andalusines en la zona meridional de l'actual País Valencià, datant la majoria d'elles dels segles X i XI (TorRó 2005: 312). Tot i això, caldrà afinar les fases i entendre els processos d'articulació entre els llocs fortificats en alçada $\mathrm{i}$ els espais agraris vinculats als fons de valls i a les àrees més fèrtils.

L'excavació del jaciment permetria també aprofundir en les problemàtiques relacionades amb la seva morfologia. Tal com hem esmentat, l'urbanisme dels llocs fortificats és una qüestió de plena vigència i el cas de Miravet podria aportar llum a alguns d'aquests interrogants. Per tant, el plantejament d'una actuació extractiva sistemàtica i en extensió a Miravet és ineludible, atès que pot aportar informacions de primer ordre al respecte de la morfologia dels habitatges, la seva articulació en forma de poblat o les interpretacions socioculturals que es desprenen d'aquestes formes agregades d'hàbitat (GuTIÉRREz 2012).

\section{AGRAÏMENTS}

Voldria reconèixer en aquest espai les correccions i comentaris dels professors Dr. Xavier Ballestín i Dra. Marta Sancho, de la Universitat de Barcelona, i de l'arqueòleg Walter Alegría. 


\section{Bibliografia}

AcIÉn, Manuel, 2008. Poblamiento y sociedad en al-Andalus: un mundo de ciudades, alquerías y husun, XVIII Semana de Estudios Medievales (Nájera 2007) 2008, pp. 141-167

Andreu, Guillem, 1975. Los antiguos términos de Miravet, Albalat y Cabanes. Notas históricas, documentales y bibliográficas en el IV centenario de su unión territorial. Boletín de la Sociedad Castellonense de Cultura 51: 213-243

-1988. Noticias históricas de la villa de Cabanes, Cabanes, Publicaciones de la Caja Rural Nuestra Señora del Buen Suceso de Cabanes: 214-223

Angelé, Sabine, Cressier, Patrice, 1990. "Velefique (Almería): un exemple de mosquée rurale en al-Andalus”, Mélanges de la Casa Velázquez, 26, 1: 112-130

Arasa, Ferran, ABAD, Lorenzo, 1989. L'Arc romà de Cabanes, Castelló, Diputació de Castelló: 30

Arasa, Ferran, Rosselló, Vicenç M., 1995. Les vies romanes del territori valencià, València, Conselleria d'Obres Públiques, Urbanisme i Transports: 121

Arquer, Neus, Falomir, Ferran, 2008. "El castell de Xivert (Alcalà de Xivert, Baix Maestrat). Campanyes d'excavació 2007 i 2008. Primeres valoracions", Quaderns de Prehistòria i Arqueologia de Castelló, 26: 207-210.

Azuar, Rafael, 1989. Dénia islámica. Arqueología y poblamiento, Alacant, Instituto de Cultura Juan Gil-Albert, Diputació Provincial d'Alacant.

-2005. "Las técnicas constructivas en la formación de al-Andalus", Arqueología de la Arquitectura, 4: 149-160.

BARCELÓ, Carmen, 1983. Toponímia aràbiga del País Valencià, p. 178.

Bazzana, André, Guichard, Pierre, 1977. "Campaña 1977 de investigación arqueológica en yacimientos medievales de la provincia de Castellón (la Magdalena, Monte Mollet, Zufera)", Cuadernos de prehistoria y arqueología castellonenses, 4: 333-350

- 1979. "Prospecciones y sondeos arqueológicos de altura en la provincia de Castellón de la Plana (campaña de 1976)”, Noticiario arqueológico hispánico, 6: 607-659

Bazzana, André, 1992. Maisons d'al-Andalus. Habitat médiéval et structures du peuplement dans l'Espagne orientale, 2, Madrid, Casa de Velázquez: 148-299

-2002. "La maison rurale dans la péninsule ibérique: un atelier d'ethno-archéologie", Ruralia, 4: $216-231$ 
-2011. “Quelques réflexions sur les caractères de l'espace domestique dans al-Andalus, et son évolution des musulmans aux chrétiens", Cristâos e Muçulmanos na Idade Média Peninsular. Encontros e Desencontros, R.V. Gomes, M.V. Gomes, C. Tente (coords.), Aljezur/Lisboa, IAP

BeTí, M. El castillo de Mirabet y sus sufragáneos. Butlletí de la Societat Castellonenca de Cultura 2 1921, pp. 300-303.

Bolòs, Jordi, 2014. "L'arqueologia del paisatge de la Catalunya medieval”, Butlletí de la Societat Catalana d'Estudis Històrics, 24: 101-170.

Boone, James L., 2009. Lost Civilization. The contested islamic past in Spain and Portugal. London: Duckworth

Calvo, Susana, 2004. "Las mezquitas de pequeñas ciudades y núcleos rurales de al-Andalus", Revista de Ciencias de las Religiones, 10: 39-63

Canivell, Jacinto, Graciani, Amparo, 2015. "Caracterización constructiva de las fábricas de tapia en las fortificaciones almohades del antiguo Reino de Sevilla” Arqueología de la Arquitectura, 12.

Carvajal, José Cristóbal, 2009. Pottery production and Islam in south-east Spain: a social model. Antiquity, 83 (320): 388-398.

CRessier, Patrice, 2001. El acarreo de obras antiguas en la arquitectura islámica de primera época. Cuadernos Emeritenses, 17: 309-334.

Flors, Enric, 2009 (coord.). Torre de la Sal (Ribera de Cabanes, Castellón). Evolución del paisaje antrópico des de la prehistoria hasta el medioevo, Castelló, Servei d'Investigacions Arqueològiques i Prehistòriques

GutiÉrRez, Sonia, 2012. "La arqueología en la historia del temprano al-Andalus: espacios sociales, cerámica e islamización", Histoire et archéologie de l'occident musulman, VIIe- Xve siècles: AlAndalus, Maghreb, Sicile; [actes du colloque, Tourtour, Fondation des Treilles, septembre 2010], P. Sénac (ed.), Toulouse: Méridiennes, études médiévales ibériques, Villa 4

—2012b. "Gramática de la casa. Perspectivas de análisis arqueológico de los espacios domésticos medievales en la península ibérica (siglos VII-XIII)". Arqueología de la Arquitectura, 9: 139-164.

Huguet, Cayetano. 1925. Nombres árabes de la provincia de Castellón o usados en ella. Butlletí de la Societat Castellonenca de Cultura, 2: 199-202. 
Llobregat, Enrique A., 1984. "La perduración de un topónimo de la Via Augusta: Lubricatum / Rahal al-Lobrecati / Turris de Lupricato". Sharq Al-Andalus, núm. 1 (1984):103-107

Lorrio, Alberto José, Sánchez de Prado, María Dolores, 2008. "El Molón (Camporrobles, Valencia). Un poblado de primera época islámica", Lvcentvm, 27: 141-164.

Malo de Molina, Manuel, 1857. Rodrigo el Campeador. Estudio Histórico, Madrid, Imprenta Nacional.

Martí, Ramón, Negre, Joan, 2014. "Fortificaciones y edilica de prestigio en el extremo oriental de la Marca Superior: Țurțūša y su entorno", La ciutat medieval i Arqueologia, F. Sabaté, J. Brufal (eds.), Lleida, Pagès: 219-239

Navarro, Julio i Robles, Alfonso, 1996. Liétor. Formas de vida rurales en Sarq al-Andalus a través de una ocultación de los siglos X-XI. Centro de Estudios Árabes y Arqueológicos "Ibn Arabí”, Múrcia.

Negre, Joan, 2013. De Dertosa a Țurțušă. L'extrem oriental d'al-Tagr al-A'là en el context del procés d'islamització d'al-Andalus, Tesi doctoral: Universitat Autònoma de Barcelona.

-2013b. "Evolució de la xarxa viària del territori de Tortosa entre l'Antiguitat i l'Edat Mitjana", Quaderns de Prehistòria i Arqueologia de Castelló, 31: 209-228.

-2014. La cerámica altomedieval de Tortosa (siglos VII-X). Una primera clasificación y análisis interpretativo. Arqueología y Territorio Medieval 21: 39-67.

-2015. "Transformacions en el poblament rural del territori de Tortosa entre l'antiguitat tardana i l'edat mitjana. Resultats de les campanyes de prospecció arqueològica a Les Terres de l'Ebre entre 2010 i 2011", Actes del V Congrés d'Arqueologia medieval i moderna a Catalunya, Barcelona, Ajuntament de Barcelona: 635-645.

Neumaier, Joachim, de Antonio, José Manuel, Vizcaíno, David, 1998. "Excavaciones de salvamento en el Castell de Xivert (Alcalá de Chivert, Castellón): avance del estudio de las fases pre y protohistóricas”, Quaderns de Prehistòria i Arqueologia de Castelló, 19: 195-219

PÉrez, Alejandro, 1979. "El cuaternario continental de la Plana de Castelló (estudio)", Cuadernos de geografía, 24: 39-54

Piqueras, Juan, Fansa, Ghaleb, 2010. "Geografia dels Països Catalans segons el Llibre de Roger d'al- Sarif al-Idrisi”, Cuadernos de Geografía, 87: 65-88

Reynolds, Paul, 1993. Settlment and pottery in the Vinalopó valley (Alicante, Spain), Oxford: Tempvs Reparatvm 
Rousset, Marie-Odile, 1988. Miravet: évolution d'un site de hauteur des musulmans aux chrétiens. Etude monographique, vols. I i II, Université de Lyon II, UER d'Histoire de l'Art et Archeologie: Memoire de Maîtrise.

Rovira I Virgili, Antoni, 1920. Història nacional de Catalunya. Barcelona: Pàtria

SANCHO, Marta, 2015. "Aprofitament de recursos i produccions en l'àmbit rural a la Catalunya medieval: aproximacions des de l'arqueologia", Estudis d'Història Agrària, 27: 137-151

Sanjaume, Eulàlia, Segura, Francisca, 1986. "Análisis morfológico y sedimentológico de la llanura aluvial entre Orpesa y La Ribera de Cabanes”, Cuadernos de Geografía, 23: 29-60

Selma, Sergi, 2014. 'Les torres nord i sud-oest del castell d'Orpesa (La Plana Alta), intervencions i recuperació", Quaderns de Prehistòria i Arqueologia de Castelló, 32: 223-234.

SÉnAC, Philippe, 2005. "Un village islamique de la vallée de l'Èbre (X-XI siècles): Las Sillas (Marcén)", Mélanges de la Casa de Velázquez. Nouvelle série, 35, 1: 335-341

SubíAs, Eva, Fiz, Ignacio, 2004. "Arqueologia del territori: docència i recerca”. Quaderns de Vilaniu, 45: 165-189

Torró, Josep, 1998. Fortificaciones en Yibâl Balansiya. Una propuesta de secuencia, en MALPICA, A (ed.), Castillos y territorio en al-Andalus, Granada.

-2005. "Terrasses irrigades a les muntanyes valencianes. Les transformacions de la colonització cristiana", Afers , 5: 301-56.

Torró, Josep. i Ferrer, P. 1985. Asentamientos altomedievales en el Pic Negre (Cocentaina, Alicante). Aportación al estudio del tránsito a la época islámica en el ámbito montañoso del País Valenciano, pàgs. 129-146, a I Congreso de Arqueología Medieval Española, Huesca: AEAM. 


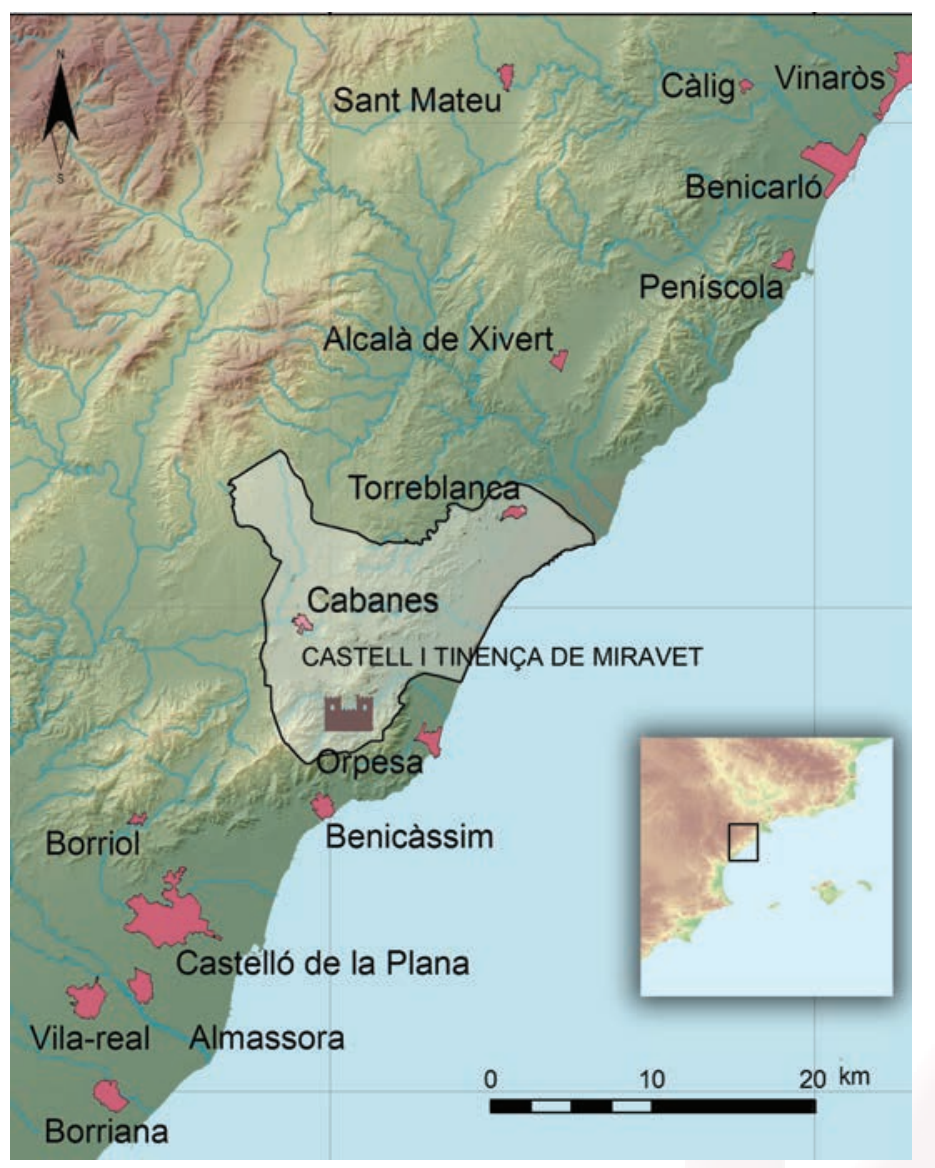

Fig. 1 Mapa de situació amb indicació dels municipis actuals. Arxiu de l'autor.

Fig. 2 Localització dels principals llocs arqueològics descrits a l'article. Arxiu de l'autor.

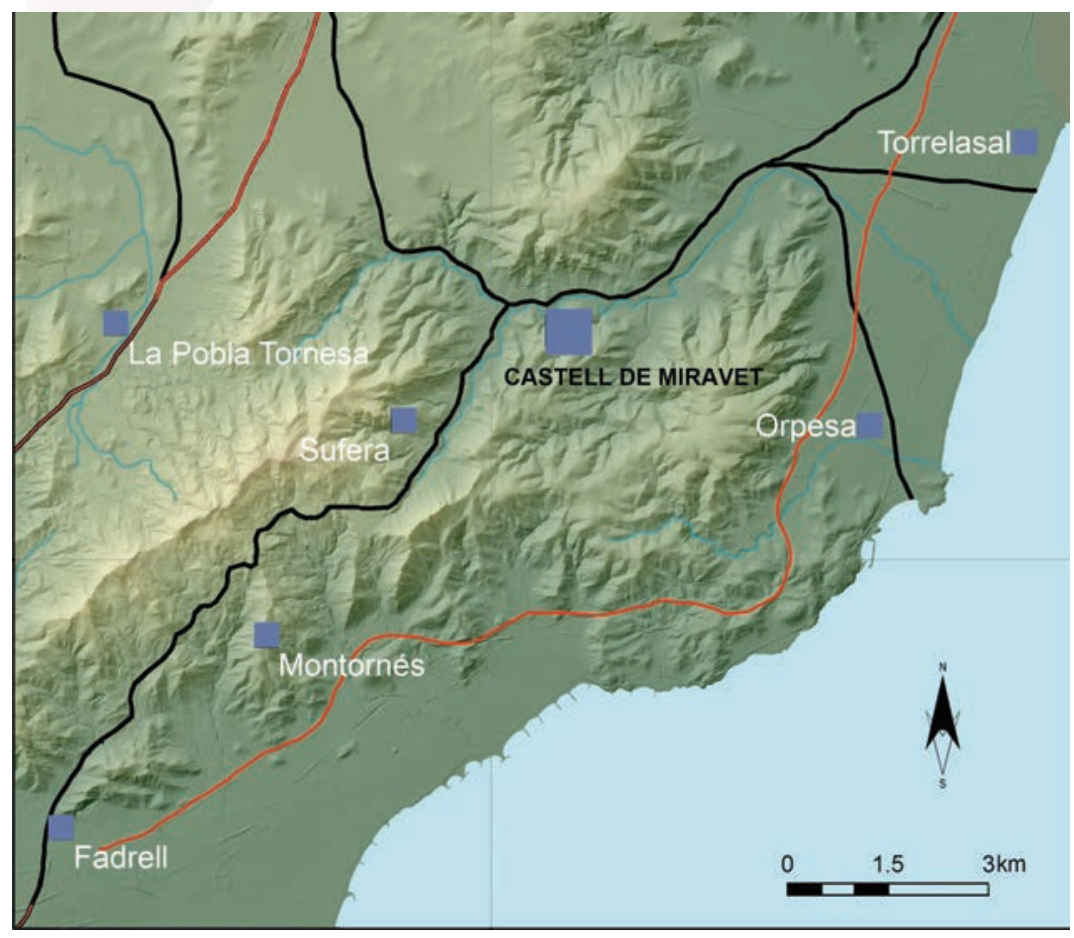




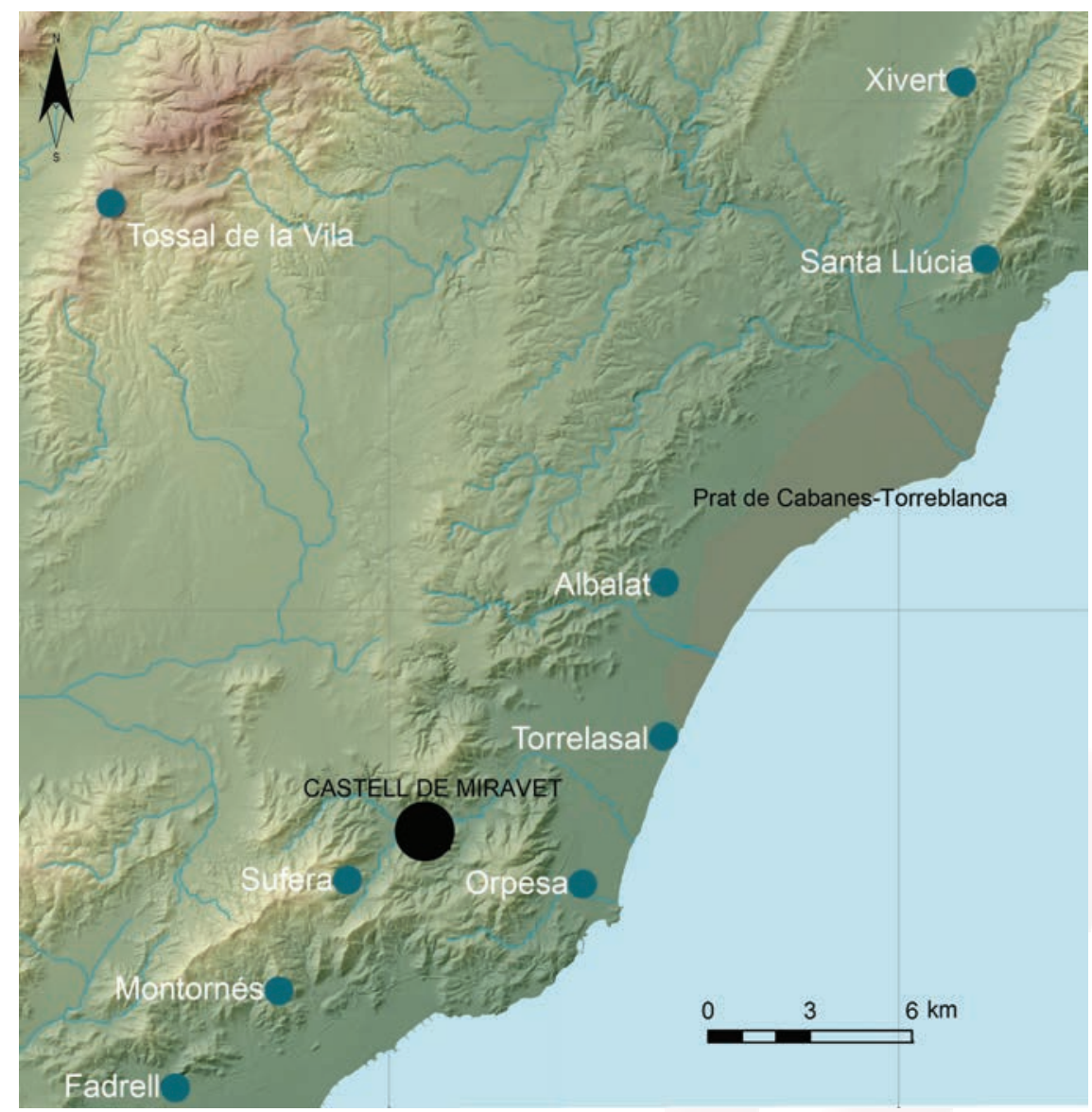

Fig. 3 Plànol de la xarxa de comunicacions amb els principals llocs arqueològics. En vermell s'indiquen les vies principals mentre que en negre, les secundàries. Arxiu de l'autor.

Fig. 4 Croquis de distribució de Miravet. Planimetria d'A. Bazzana.

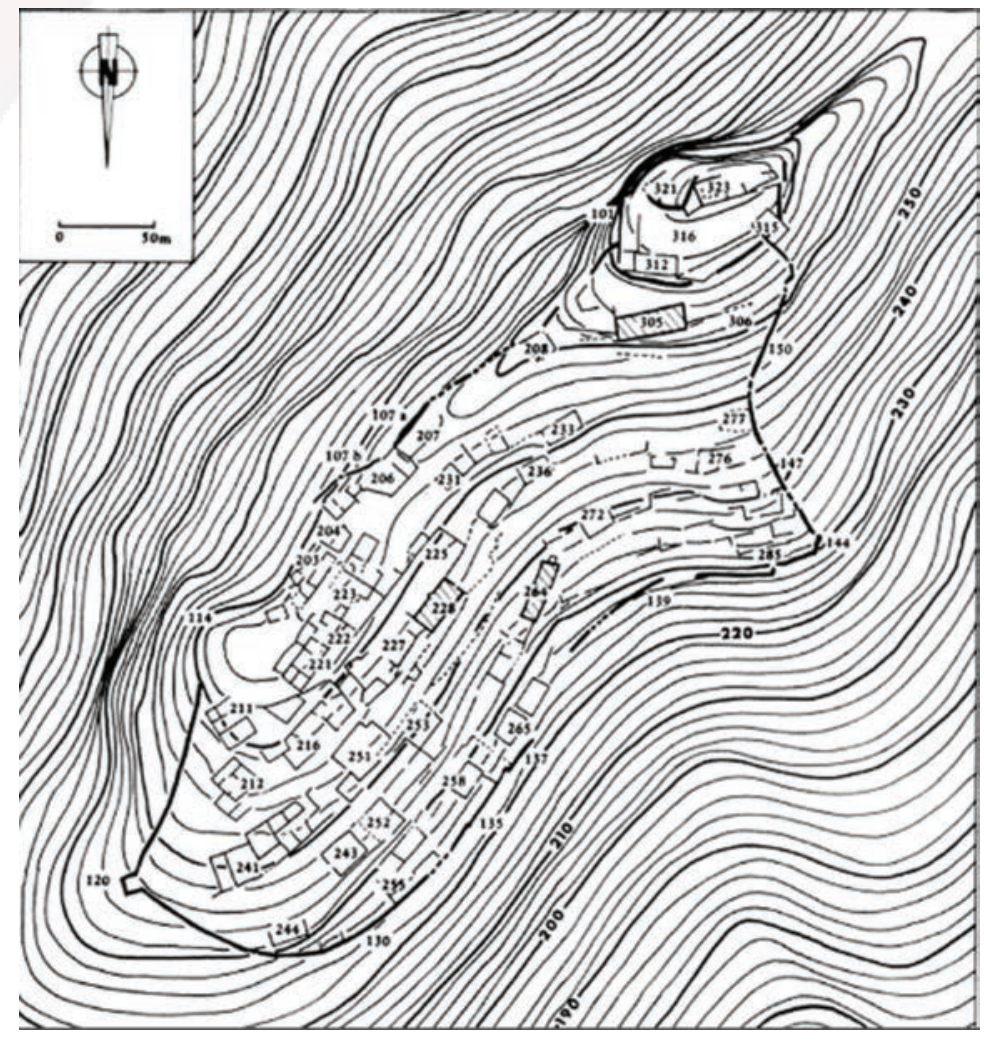


Fig. 5 Detall de les diferents tècniques constructives da la muralla del recinte superior. Arxiu de l'autor.
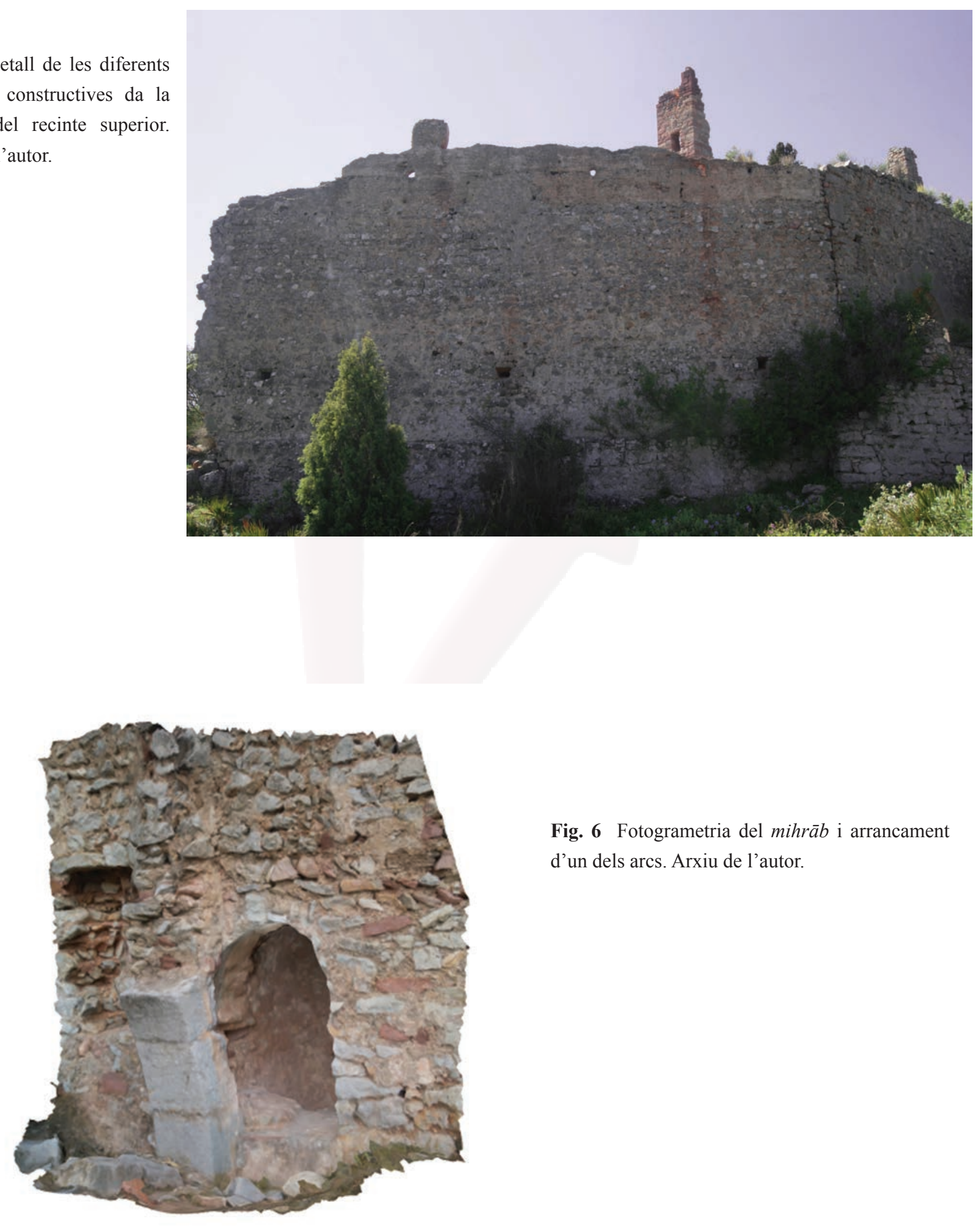

Fig. 6 Fotogrametria del mihrāb i arrancament d'un dels arcs. Arxiu de l'autor. 


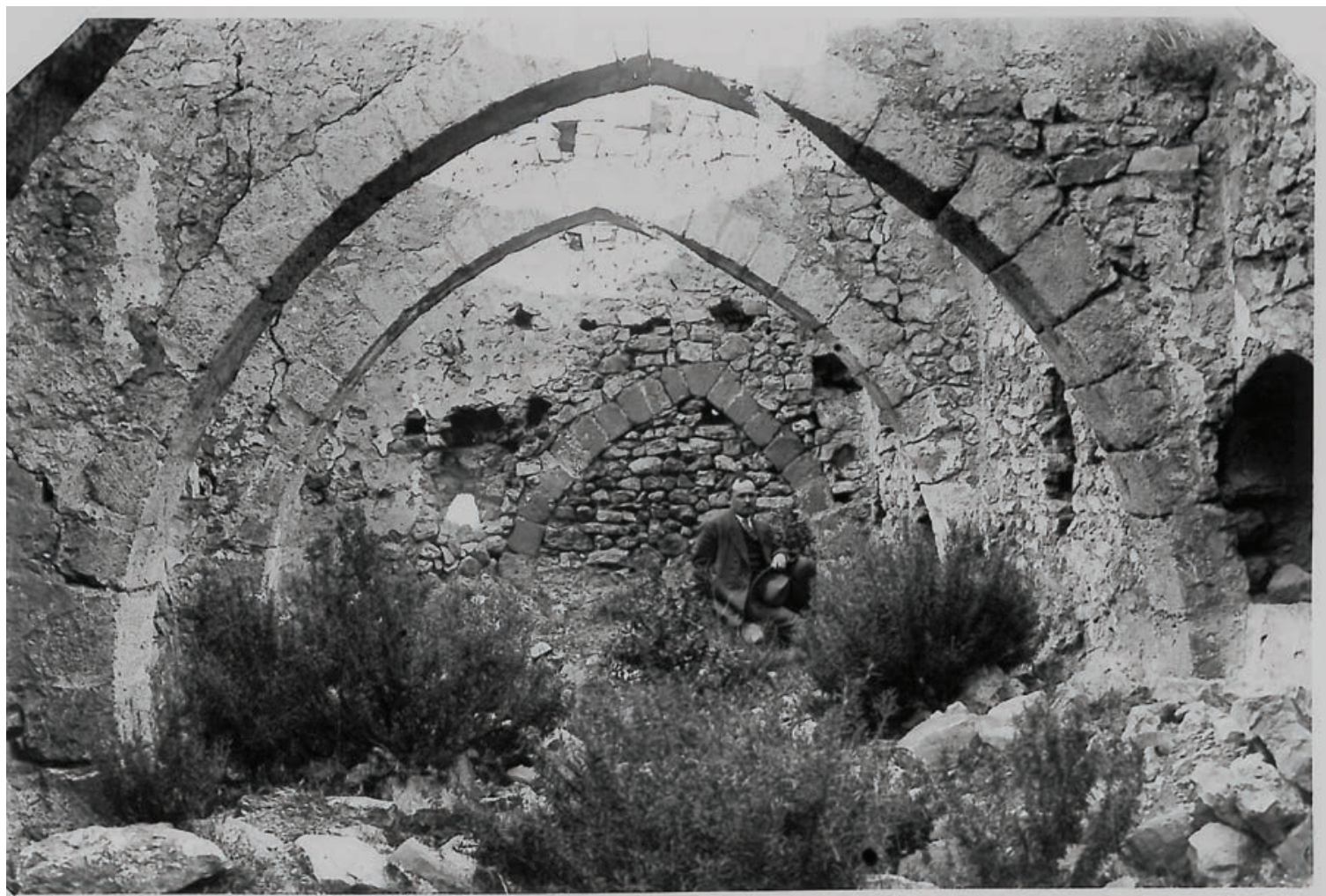

Fig. 7 Fotografia de l'interior de la mesquita-església presa el 1919. Arxiu Mas (Diputació de Castelló)

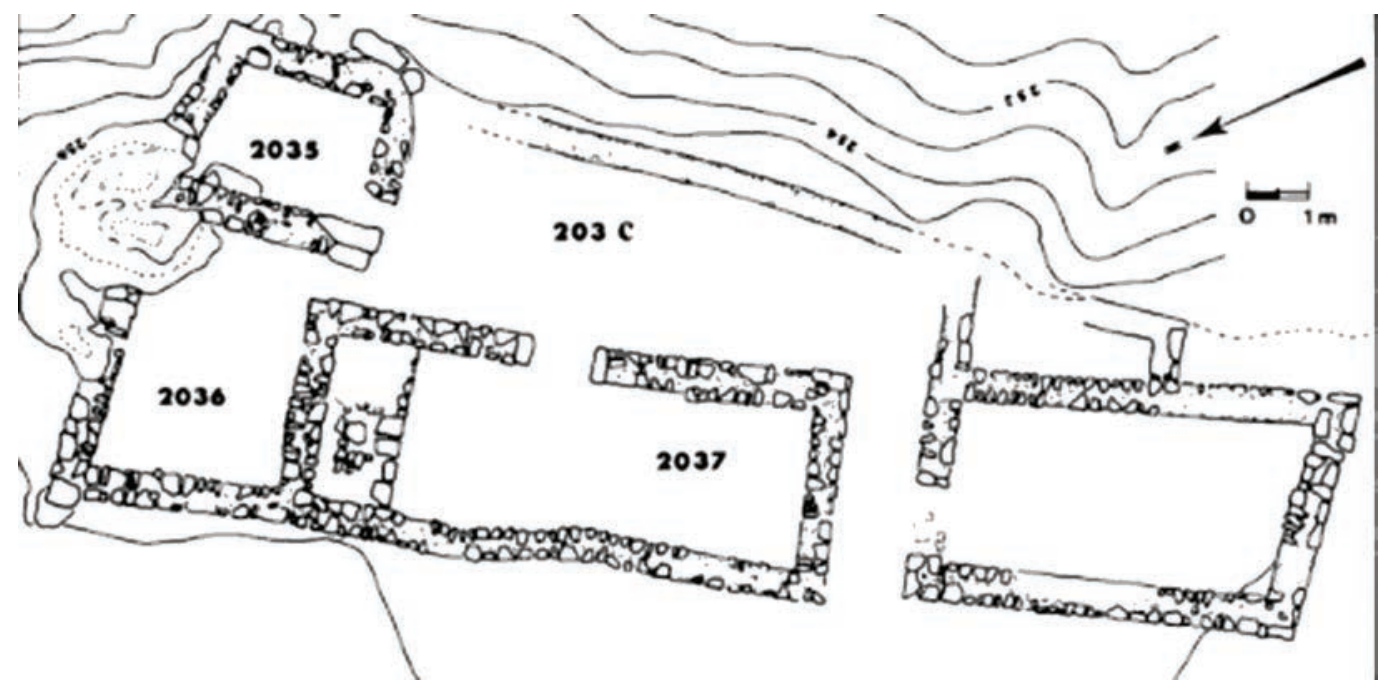

Fig. 8 Distribució de l'habitatge 203. Planimetria d'A. Bazzana. 